\title{
AVALIAÇÃO + NORMALIZAÇÃO: DESIGN COMO MODERADOR NA ANÁLISE DE BENS DE CONSUMO
}

\section{EVALUATION + STANDARDIZATION: DESIGN AS A MODERATOR IN THE ANALYSIS OF CONSUMER GOODS}

\author{
Walter Correia ${ }^{1}$, D.Sc. \\ walter.franklin@ufpe.br e https://orcid.org/0000-0002-6491-9783 \\ Weynner dos Santos ${ }^{1}$, M.Sc. \\ wkbs@cin.ufpe.br e https://orcid.org/0000-0001-7420-8718 \\ Fábio Campos ${ }^{1}$, D.Sc. \\ fc2005@gmail.com e https://orcid.org/0000-0002-7882-876X \\ André Santos ${ }^{2}$, D.Sc. \\ alsantos@inmetro.gov.br e https://orcid.org/0000-0002-0840-5120 \\ Maria Luiza Martins, ${ }^{2}$, D.Sc \\ malumarts@gmail.com e https://orcid.org/0000-0001-9069-3063
}

\footnotetext{
${ }^{1} \mathrm{LaCA}^{2} \mathrm{I}$ - Lab. de Conc. e Análise de Artrf. Inteligentes, UFPE, CAC, Design, Av dos Reitores, s/n, Recife-PE, Brazil

${ }^{2}$ Inmetro, Rua Santa Alexandrina, 416 - Rio Comprido, Rio de Janeiro - RJ, Brazil
}

embalagem, avaliação de produtos, usabilidade, segurança

O design das embalagens dos produtos depende do conhecimento de diferentes áreas, incluindo aquelas voltadas para a qualidade mecânica, como em Engenharia Mecânica, Química e de Produção, e outras informacionais e comunicativas, como em Design de Produto e Gráfico. É nesse contexto no qual esta pesquisa se debruça ante uma demanda do Inmetro na avaliação de usabilidade de embalagens. Durante o desenvolvimento desta, foi feito o uso de padrões nacionais de qualidade e de segurança para definir o campo de estudo, selecionar as baterias de teste e as diretrizes regulatórias, além de escolher as quantidades de amostra e perfis. Porém, mesmo com a diversidade dessas normas estabelecidas pela ABNT (2020) e pela ISO (2020) existe ainda uma lacuna quanto às diretrizes que tratam da ergonomia e usabilidade de produtos não digitais, principalmente no que diz respeito à interação com usuários reais. Neste artigo, são analisados três diferentes modelos de embalagens comuns a diferentes alimentos, de vinte fabricantes diferentes. Os métodos, ferramentas, ambiente de teste, seleção de amostra e seleção de participantes são descritos na seção de metodologia do próximo tópico. Os resultados de fato apontam para o que se pode definir como uma maior preocupação que as empresas devem ter em relação a qualidade destes tipos de embalagens.

package, product design evaluation, usability, safety

The design of packaging products depends on knowledge of different areas, including those focused on mechanical quality, such as in Mechanical, Chemical and Production Engineering, and other informational and communicative areas, such as in Product Design and Graphics. It is in this context that this research focuses on a demand from Inmetro in evaluating the usability of packaging. During its development, use was made of national quality and safety standards to define the field of study, select test batteries and regulatory guidelines, and choose sample quantities and profiles. However, even with the diversity of these standards established by ABNT (2020) and ISO (2020) there is still a gap in the guidelines that deal with ergonomics and usability of non-digital products, especially about interaction with real users. In this article, three different packaging models common to different foods from twenty different manufacturers are analyzed. Methods, tools, testing environment, sample selection and participant selection are described in the methodology section of the next topic. The results in fact point to what can be defined as a major concern that companies should have in relation to the quality of these types of packaging.

Recebido em: 17 / $03 / 2021$

Aceito em: $30 / 06 / 2021$

DOI: http://dx.doi.org/10.22570/ergodesignhci.v9i1.1565 


\section{Introdução}

O projeto das embalagens de produtos depende de conhecimentos de diversas áreas, incluindo aquelas voltadas à qualidade mecânica, como nas Engenharias Mecânica, Química, de Produção; e outras informacionais e comunicativas, como no Design de Produto, no Design Gráfico e no Marketing. Na questão da interação do usuário com embalagens, isso é, nas ações necessárias para o manuseio desses artefatos, como na abertura, no fechamento, no descarte e no reaproveitamento, algumas disciplinas mais específicas contribuem com a análise do comportamento das pessoas e de como o produto afeta seu dia a dia.

É nisso que a Ergonomia e a Usabilidade trabalham, para propor, avaliar e melhorar questões de qualidade relativas à Experiência do Usuário. Elas existem normalmente associadas às ciências criativas do Design e analíticas da Engenharia de Produto e de Software. O Instituto Nacional de Metrologia, Qualidade e Tecnologia - o INMETRO (2020) - é o responsável por avaliar a qualidade e a segurança das embalagens de produtos. Ele iniciou e gerenciou um projeto para estudar a ergonomia e a usabilidade desses invólucros e, para isso, contou com a participação do Laboratório de Concepção e Análise de Artefatos Inteligentes - o $\mathrm{LaCA}^{2} \mathrm{I}$ - da Universidade Federal de Pernambuco.

É comum, durante os projetos do Inmetro, recorrer às normas técnicas, internacionais, regionais, nacionais e estrangeiras, para definir o campo de estudo, selecionar as baterias de teste e as diretrizes reguladoras, além de escolher quantidade e perfis de amostra. Contudo, mesmo com a diversidade dessas normas estabelecidas pela Associação Brasileira de Normas Técnicas, a ABNT (2020); e pela Organização Internacional para Normalização, em inglês, International Organization for Standardization, ou ISO (2020); há uma lacuna referente às diretrizes que tratem da ergonomia e da usabilidade de produtos não digitais, especialmente no que tange à interação com usuários reais. Isso porque, a maior parte de seus ensaios é realizada com grupos de especialistas.

Consonante a isso, mesmo aquelas normas/guias que tratam de questões como inteligibilidade textual, tais como a ISO/IEC Guide 37 (2012); são omissas quanto aos detalhes da metodologia de verificação a ser aplicada para a verificação da conformidade dos produtos aos atributos de normalização, limitando-se a tratar dos conceitos num nível de abstração muito alto, tais como "painel de usuários" e "análise por especialistas". Não há especificação, mesmo que genérica, da implementação dessas estratégias e suas implicações quanto à abrangência, à validade e à classificação dos resultados obtidos.

Tais omissões podem fragilizar a capacidade para a análise pelos times dos organismos responsáveis, constituindo, inclusive, grande parte das queixas e contestações apresentadas pelos fabricantes. Os estudos aqui seguiram padrões de outros estudos já realizados junto ao Programa de Análise de Produtos (PAP) do Inmetro. De maneira geral este programa tem como principais objetivos (Tabela 1), dentre outros:

\begin{tabular}{l}
\hline Objetivos do Programa \\
\hline Trazer informação ao consumidor brasileiro acerca do panorama do mercado em termos de conformidade, de \\
adequação de produtos e serviços aos critérios estabelecidos em normas e regulamentos técnicos, \\
contribuindo para que ele faça escolhas mais bem fundamentadas em suas decisões de compra, ao levar em \\
consideração outros atributos além do preço e, por consequência, torná-lo parte integrante do processo de \\
melhoria da indústria nacional; e \\
A apresentação de subsídios para o aumento da competitividade da indústria nacional. \\
\hline
\end{tabular}

Tabela 1. Principais objetivos do Programa de Análise de Produtos do Inmetro.

Ressalta-se que as análises que são feitas pelo Programa não têm caráter de fiscalização, e que em nenhum momento tais testes e ensaios se destinam à aprovação de produtos ou serviços, e sim, para servir de base para futuras análises pelas empresas dos referidos produtos bem como para outros fabricantes de embalagens e produtos que apresentem alguma similaridade com os estudados neste projeto.

Neste artigo, foram analisados três modelos distintos de embalagens comuns a diversos produtos alimentícios em território nacional, de vinte fabricantes distintas. Tais embalagens passaram por baterias de 
testes com usuários, a fim de se obter resultados a partir da visão do projetista e da visão real da pessoa que compra e consome tais alimentos. Os métodos, as ferramentas, o ambiente de testes, a escolha das amostras e a seleção dos participantes estão descritas na seção metodologia do tópico seguinte.

\section{Metodologia}

Para o desenvolvimento e encaminhamento das análises, definiu-se como base para a metodologia, uma revisão assistemática de literatura (i) de casos similares, junto à internet e ao banco de dados do Inmetro; (ii) Testes de Ergonomia e Usabilidade; sendo a primeira com caráter experimental fornecido pelo corpo técnico do $\mathrm{LaCA}^{2} \mathrm{I}$, e a segunda com o uso de consumidores em testes simulados em laboratório.

Foi executada uma avaliação heurística, que segundo NIELSEN (2012), tem por objetivo encontrar problemas de utilização na concepção de modo que eles possam ser atendidos como parte de um processo iterativo de design. Define-se como estudo heurístico (GIGERENZER \& GAISSMEIER, 2011) todo aquele que trabalha com a racionalização de dados pouco ou nada racionais, além de seus resultados serem derivados de verdades assumidas a partir da recorrência dos fatos. O quasi-experimento (MORGAN, 2000) conduziu os usuários a testes simulados, os quais tiveram como foco respostas a questionários semiestruturados. Ressalta-se que os usuários tiveram acesso a todas as informações das respectivas embalagens envolvidas no estudo.

\subsection{Do Ambiente de Testes}

Os testes foram realizados com o apoio do $\mathrm{LaCA}^{2} \mathrm{I}$ - Laboratório de Concepção e Análise de Artefatos Inteligentes - do Departamento de Design da Universidade Federal de Pernambuco (UFPE, 2020). Os pesquisadores do espaço responsáveis pela supervisão e aplicação dos testes tinham um currículo extenso nos campos da Experiência do Usuário, da Ergonomia, da Usabilidade e dos Estudos de Consumo, especificamente das Técnicas de Avaliação da Adoção de Novos Produtos.

O ambiente de testes foi montado para receber até dois membros da equipe de pesquisa mais o usuário, além da disposição de todas as embalagens utilizadas na jornada de avaliação dos produtos. O espaço contou ainda com rede de internet do tipo wi-fi ativa, uma câmera de vídeo para captura dos procedimentos, e computador para tabulação dos dados em tempo real, posteriormente revisados com os dados das gravações. Para a elaboração e aplicação dos questionários, foi utilizado o Google Drive, que apresenta uma interface consideravelmente intuitiva para a condução das entrevistas. O questionário foi desenvolvido pelo próprio $\mathrm{LaCA}^{2} \mathrm{I}$, sendo possível acessar os documentos de qualquer dispositivo digital com internet, com senha, para aplicação junto aos usuários.

\subsection{Definição e Agrupamento das Amostras}

Segundo o Guia de Embalagens elaborado para uso nas Olimpíadas do Rio 2016 (RIO DE JANEIRO, 2013), os tipos de embalagens podem ser divididas quanto ao uso: (i) embalagem primária (ou embalagem de venda), sendo qualquer embalagem que esteja em contato direto com o produto e que tenha contato direto com o consumidor final no ponto de compra; (ii) embalagem secundária (ou embalagem grupada), como qualquer embalagem que tenha por objetivo agrupar um determinado número de unidades de venda, sendo que as características do produto não serão alteradas se removida; e (iii) embalagem terciária (ou embalagem de transporte), sendo qualquer tipo de embalagem que tem por objetivo facilitar a logística das embalagens secundárias e/ou primárias, contribuindo para que não haja danos aos produtos movimentados.

Embalagens também podem ser classificadas quanto à destinação temporária, sendo produzidas considerando as seguintes destinações: (a) embalagem descartável, a qual será exclusa após a primeira utilização. Para isso, ela pode ter uma estrutura mais simples, usando menos matéria-prima na sua 
formulação e consumindo menos energia para o seu processamento. (b) Embalagem retornável, que retornará ao processo de fabricação do produto para re-envasamento, passando por processos de lavagem e esterilização, bem como pelas etapas de transporte da logística reversa. Finalmente, (iii) embalagem reutilizável, que será reaproveitada pelo consumidor para o acondicionamento de outros produtos, sem prejudicar a saúde e a segurança do consumidor (RIO DE JANEIRO, 2013).

No caso das embalagens analisadas nesta pesquisa, elas podem ser consideradas como (i) primárias e (a) descartáveis. Para a análise das embalagens foram utilizadas seis marcas de pão bisnaga e macarrão, com embalagem plástica do tipo saco; oito marcas de barra de cereal com embalagens plásticas com laminação interna; e seis marcas de enlatados, no formato barra e cilindro, com abertura por alça anelar. Ressalta-se que na ocasião, as embalagens de lata eram o produto mais citado no Sistema Inmetro de Monitoramento de Acidentes de Consumo (Sinmac), com 5,35\% de registros de acidentes - por esse motivo esta embalagem foi selecionada para análise.

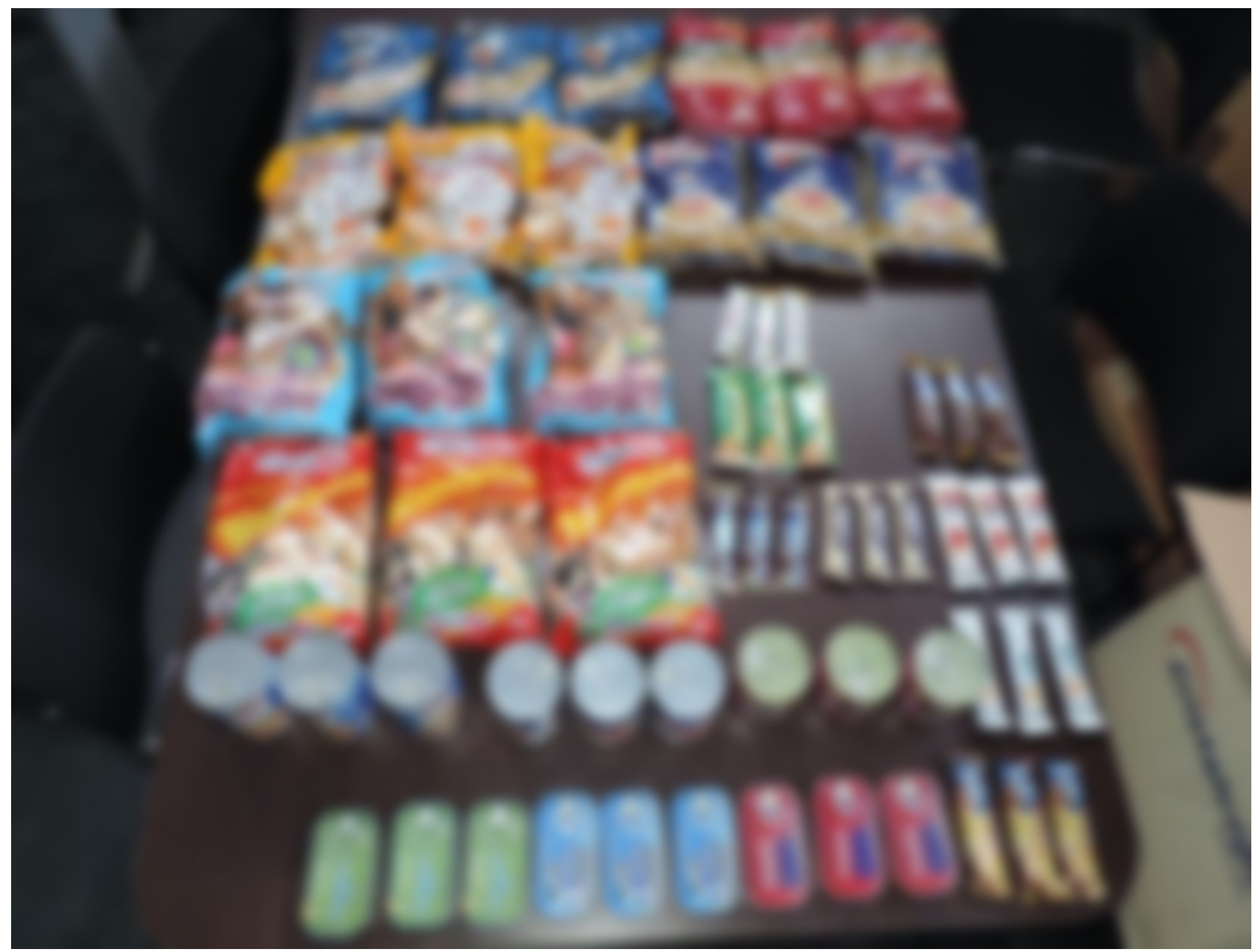

Figura 1. Conjunto das embalagens avaliadas

Mesmo tendo sido as marcas e os tipos dos produtos estudados publicizados e previamente divulgados em matéria jornalística (FANTÁSTICO, 2015), seus nomes serão ocultos neste trabalho, sendo que é importante salientar que as marcas terem sucesso ou fracasso nos testes não indica má qualidade dos produtos, ainda mais porque, no momento de realização desses testes, a usabilidade dos produtos ainda não era averiguada pelo Inmetro (e nenhum outro órgão regulamentador, justamente por não ser um tema regulado), tornando impossível aos fabricantes prever ou ter conhecimento sobre quais parâmetros de usabilidade deveriam seguir. A Tabela 2 a seguir resume os modelos avaliados, relacionando as marcas, os tipos de embalagem e 
algumas especificações técnicas relevantes. Foram colocadas nomenclaturas conforme segue-se na tabela a seguir, e ao lado o tipo de embalagem e a especificação do produto (colunas 2 e 3 respectivamente).

\begin{tabular}{|c|c|c|c|c|}
\hline \multirow[b]{2}{*}{ "Marca" } & \multirow[b]{2}{*}{ Tipo de Embalagem } & \multicolumn{3}{|c|}{ Especificação Técnica } \\
\hline & & Conteúdo & Peso Líq. & $\begin{array}{l}\text { Dimensões (A X } \\
\text { C X P) }\end{array}$ \\
\hline $\mathrm{BC} 1$ & $\begin{array}{l}\text { Embalagem plástica laminada com } \\
\text { lacre de fita }\end{array}$ & Barra de Cereal & $25 \mathrm{~g}$ & $4,2 \times 14 \times 1,2 \mathrm{~cm}$ \\
\hline $\mathrm{BC} 2$ & $\begin{array}{l}\text { Embalagem plástica laminada com } \\
\text { lacre de fita }\end{array}$ & Barra de Cereal & $20 \mathrm{~g}$ & $\begin{array}{l}3,5 \times 13,5 \times 1,3 \\
\mathrm{~cm}\end{array}$ \\
\hline $\mathrm{BC} 3$ & $\begin{array}{l}\text { Embalagem plástica laminada com } \\
\text { lacre de fita }\end{array}$ & Barra de Cereal & $22 \mathrm{~g}$ & $\begin{array}{l}4,2 \times 13,5 \times 1,3 \\
\mathrm{~cm}\end{array}$ \\
\hline $\mathrm{BC} 4$ & $\begin{array}{l}\text { Embalagem plástica laminada com } \\
\text { lacre de fita }\end{array}$ & Barra de Cereal & $22 \mathrm{~g}$ & $3,7 \times 12 \times 0,7 \mathrm{~cm}$ \\
\hline BC5 & $\begin{array}{l}\text { Embalagem plástica laminada com } \\
\text { lacre de fita }\end{array}$ & Barra de Cereal & $20 \mathrm{~g}$ & $\begin{array}{l}4,5 \times 12,5 \times 1,2 \\
\mathrm{~cm}\end{array}$ \\
\hline BC6 & $\begin{array}{l}\text { Embalagem plástica laminada com } \\
\text { lacre de fita }\end{array}$ & Barra de Cereal & $20 \mathrm{~g}$ & $4 \times 14,1 \times 1,3 \mathrm{~cm}$ \\
\hline $\mathrm{BC7}$ & $\begin{array}{l}\text { Embalagem plástica laminada com } \\
\text { lacre de fita }\end{array}$ & Barra de Cereal & $21 \mathrm{~g}$ & $5 \times 13,5 \times 1 \mathrm{~cm}$ \\
\hline $\mathrm{BC} 8$ & $\begin{array}{l}\text { Embalagem plástica laminada com } \\
\text { lacre de fita }\end{array}$ & Barra de Cereal & $20 \mathrm{~g}$ & $\begin{array}{l}4,2 \times 13,8 \times 1,2 \\
\mathrm{~cm}\end{array}$ \\
\hline AN1 & $\begin{array}{l}\text { Embalagem metálica com abertura } \\
\text { tipo "anel" }\end{array}$ & $\begin{array}{l}\text { Sardinha em molho } \\
\text { ou azeite }\end{array}$ & $125 \mathrm{~g}$ & $\begin{array}{l}2,7 \times 10,5 \times 5,5 \\
\mathrm{~cm}\end{array}$ \\
\hline AN2 & $\begin{array}{l}\text { Embalagem metálica com abertura } \\
\text { tipo "anel" }\end{array}$ & $\begin{array}{l}\text { Sardinha em molho } \\
\text { ou azeite }\end{array}$ & $125 \mathrm{~g}$ & $\begin{array}{l}2,7 \times 10,5 \times 5,5 \\
\mathrm{~cm}\end{array}$ \\
\hline AN3 & $\begin{array}{l}\text { Embalagem metálica com abertura } \\
\text { tipo "anel" }\end{array}$ & $\begin{array}{l}\text { Sardinha em molho } \\
\text { ou azeite }\end{array}$ & $125 \mathrm{~g}$ & $\begin{array}{l}2,7 \times 10,5 \times 5,5 \\
\mathrm{~cm}\end{array}$ \\
\hline AN4 & $\begin{array}{l}\text { Embalagem metálica com abertura } \\
\text { tipo "anel" }\end{array}$ & $\begin{array}{l}\text { Salsicha do tipo em } \\
\text { conserva }\end{array}$ & $400 \mathrm{~g}$ & $\begin{array}{l}10,9(\mathrm{~A}) \times 7,5(\mathrm{D}) \\
\mathrm{cm}\end{array}$ \\
\hline AN5 & $\begin{array}{l}\text { Embalagem metálica com abertura } \\
\text { tipo "anel" }\end{array}$ & Comida para Gatos & $290 \mathrm{~g}$ & $\begin{array}{l}8,3(\mathrm{~A}) \times 7,4(\mathrm{D}) \\
\mathrm{cm}\end{array}$ \\
\hline AN6 & $\begin{array}{l}\text { Embalagem metálica com abertura } \\
\text { tipo "anel" }\end{array}$ & Fiambre compactado & $320 \mathrm{~g}$ & $\begin{array}{l}9,1(\mathrm{~A}) \times 7,5(\mathrm{D}) \\
\mathrm{cm}\end{array}$ \\
\hline PB1 & $\begin{array}{l}\text { Embalagem Plástica com lacre de } \\
\text { contato }\end{array}$ & Pão tipo Bisnaguinha & $300 \mathrm{~g}$ & $\begin{array}{l}31,5 \times 21,5 \times 3 \\
\mathrm{~cm}\end{array}$ \\
\hline PB2 & $\begin{array}{l}\text { Embalagem Plástica com lacre de } \\
\text { contato }\end{array}$ & Pão tipo Bisnaguinha & $300 \mathrm{~g}$ & $\begin{array}{l}31,5 \times 21,5 \times 3,4 \\
\mathrm{~cm}\end{array}$ \\
\hline PB3 & $\begin{array}{l}\text { Embalagem Plástica com lacre de } \\
\text { contato }\end{array}$ & Pão tipo Bisnaguinha & $300 \mathrm{~g}$ & $\begin{array}{l}31,5 \times 21,5 \times 2,7 \\
\mathrm{~cm}\end{array}$ \\
\hline MP1 & $\begin{array}{l}\text { Embalagem Plástica com lacre de } \\
\text { contato }\end{array}$ & $\begin{array}{l}\text { Macarrão tipo } \\
\text { parafuso }\end{array}$ & $500 \mathrm{~g}$ & $\begin{array}{l}25,5 \times 19,8 \times 4,4 \\
\mathrm{~cm}\end{array}$ \\
\hline MP2 & $\begin{array}{l}\text { Embalagem Plástica com lacre de } \\
\text { contato }\end{array}$ & $\begin{array}{l}\text { Macarrão tipo } \\
\text { parafuso }\end{array}$ & $500 \mathrm{~g}$ & $\begin{array}{l}27 \times 11,5 \times 4,8 \\
\mathrm{~cm}\end{array}$ \\
\hline MP3 & $\begin{array}{l}\text { Embalagem Plástica com lacre de } \\
\text { contato }\end{array}$ & $\begin{array}{l}\text { Macarrão tipo } \\
\text { parafuso }\end{array}$ & $500 \mathrm{~g}$ & $\begin{array}{l}26,5 \times 19,3 \times 4,3 \\
\mathrm{~cm}\end{array}$ \\
\hline
\end{tabular}

Tabela 2 - Descrição das embalagens analisadas (produção dos autores).

As amostras foram adquiridas pelo Inmetro por meio da Rede Brasileira de Metrologia e Qualidade (RBMLQ-I), formada pelos órgãos delegados do Inmetro nos Estados e enviados ao LaCA²I, na UFPE. Já que a premissa do Programa de Análise de Produtos do Inmetro é avaliar uma possível tendência da qualidade no mercado, sem se tornar uma ação de caráter fiscalizador, não há a necessidade da aquisição de amostras de todas as marcas disponíveis no mercado, mas sim, busca-se analisar uma amostra representativa, com a aquisição de marcas mais conhecidas, incluindo marcas regionais.

\subsection{Seleção dos Participantes}

O processo de seleção simples para as análises tinha em vista corresponder os usuários às características dos produtos que foram analisados, isso é, artefatos que a maioria das pessoas comumente utilizam. Dentro desta perspectiva, a Universidade Federal de Pernambuco foi um local adequado para esta seleção, e os voluntários (com as devidas assinaturas de TCLE - Termo de Consentimento Livre e Esclarecido) foram conduzidos ao $\mathrm{LaCA}^{2} \mathrm{I}$ diariamente, após agendamento prévio. 
Não houve intenção de separar estes usuários por classes sociais, tendo em vista que estes produtos são consumidos por praticamente todas elas. Além disso, não era objetivo do estudo constranger qualquer usuário. As simulações recorreram a 14 usuários por conjunto de análise das embalagens, perfazendo um total de 280 avaliações. Os usuários possuíam entre 18 e 38 anos, do sexo masculino e feminino, e todos com alguma familiaridade com as embalagens analisadas.

\section{Ergonomia e Usabilidade de Embalagens}

Segundo SOARES (1998), atualmente um grande volume de produtos alcançou nível muito altos de complexidade, algo que comumente não é aceito pelos seus usuários, mesmo que o grau de tecnologia e satisfação sejam grandes atrativos destes produtos. "Para estes produtos, faltam maturidade e conteúdo funcional dos quais os usuários realmente necessitam (...). Os consumidores desejam encontrar nos produtos, segurança, eficiência, conforto e prazer" (SOARES, 1998).

No estudo das embalagens, é comum não dar importância às suas próprias questões de segurança, isso porque, na maioria das vezes, seu conteúdo é mais relevante que a embalagem em si. Contudo, são as embalagens de um produto o primeiro meio de interação do usuário com o artefato, antecedendo o uso do artefato comercial. A embalagem é o que chama a atenção do usuário para adquirir o produto, informando nome, modelo, marca, características, funcionamento, vida útil, código de identificação e código de comercialização (MAGALHÃES, 2006). Dessa forma, embalagens também precisam lidar com os mesmos aspectos de interação comuns a qualquer produto de qualquer natureza, sendo eles listados na Tabela 3 abaixo:

\begin{tabular}{|c|c|}
\hline Aspecto de Interação & Descrição \\
\hline Intuitividade & $\begin{array}{l}\text { É avaliada a forma como as embalagens guiam seus usuários em sua leitura e seu manuseio. A } \\
\text { maneira como a estética (cor, textura, tamanho, peso, forma) influencia no uso correto além do } \\
\text { modo como suas interfaces priorizam e hierarquizam as informações nela contidas. }\end{array}$ \\
\hline Simplificação & $\begin{array}{l}\text { Consiste na clareza e na objetividade com que as informações são recebidas, decodificadas e } \\
\text { compreendidas pelos usuários das embalagens. Ela influencia na velocidade deste processo e na } \\
\text { diminuição dos caminhos que cada embalagem necessita oferecer para permitir que o usuário } \\
\text { alcance seu objetivo. }\end{array}$ \\
\hline Visibilidade & $\begin{array}{l}\text { Trata da escolha de ícones e de caracteres textuais de fácil leitura, com cores e formas } \\
\text { agradáveis e na linha de conforto suportada. São consideradas as variáveis da idade, do gênero e } \\
\text { da capacidade dos usuários envolvidos. }\end{array}$ \\
\hline Mapeamento & $\begin{array}{l}\text { Lida com o registro do itinerário de uso, isso é, o passo-a-passo para a realização da atividade, e } \\
\text { se cada etapa é condizente e corretamente ordenada para o fim da embalagem. Se um usuário } \\
\text { tenta fechar uma embalagem quando na verdade queria abri-la, ou se um produto tóxico prioriza } \\
\text { as informações de validade do produto em vez dos alertas de risco do uso deste, é porque tais } \\
\text { produtos possuem erros de itinerário. }\end{array}$ \\
\hline Feedback & $\begin{array}{l}\text { São avaliados que tipos de feedback (visual, sonoro e/ou táctil) são providenciados pelas } \\
\text { embalagens, além da velocidade com que eles são compreendidos. }\end{array}$ \\
\hline Tolerância a Erros & $\begin{array}{l}\text { Procura se identificar como a interface das embalagens providencia informações para evitar o } \\
\text { mau uso e, caso ele tome uma decisão que o prejudique, será avaliado como a embalagem tenta } \\
\text { desfazer ações ou mesmo prevenir que estas aconteçam. }\end{array}$ \\
\hline Interação Mediada & $\begin{array}{l}\text { Trata da facilidade na execução de funções, na busca por informações, na compreensão estética } \\
\text { e no nível de intuição permitido pelo uso. }\end{array}$ \\
\hline Inteligibilidade & $\begin{array}{l}\text { Avalia formas de reduzir as palavras e expressões ao seu significado mínimo e direto, a fim de se } \\
\text { obter clareza e objetividade em textos. }\end{array}$ \\
\hline Frustração / Dissonância & $\begin{array}{l}\text { Para se medir tais quesitos, é preciso estudar as variações de tempo em que cada tipo de usuário } \\
\text { leva para realizar uma tarefa no uso de uma interface, neste caso, quanto tempo ele leva para } \\
\text { abrir e fechar as embalagens; se a força aplicada por eles é o suficiente para abrir ou se excede o } \\
\text { necessário; quanto tempo eles levam para encontrar determinada informação. Quanto maior } \\
\text { forem essas grandezas, maior o grau de frustração. O grau de dissonância refere-se ao quão } \\
\text { perto ou longe a interface está da realidade do usuário. }\end{array}$ \\
\hline Segurança & $\begin{array}{l}\text { Parâmetros como evitar quinas vivas, fornecer acabamentos que evitem o deslize da pega, } \\
\text { apresentar aspecto (tamanho, peso, reflexão de luz na superfície) adequado ao uso do produto, } \\
\text { além do respeito às diferenças antropométricas; devem ser avaliados a fim de determinar o nível } \\
\text { de segurança de um produto. }\end{array}$ \\
\hline
\end{tabular}




\begin{tabular}{|l|l|}
\hline $\begin{array}{l}\text { Satisfação / Experiência } \\
\text { de Uso }\end{array}$ & $\begin{array}{l}\text { Para se gerar uma boa experiência de uso, é preciso que seja gerada uma afordância }{ }^{1} \text {. Nesse } \\
\text { sentido, o que o usuário imagina como embalagem ideal precisa ser correspondido com a versão } \\
\text { real daquele tipo de embalagem. Quanto menor a distância entre essas duas versões, maior a } \\
\text { satisfação. Para isso, as atividades de uso permitidas pela embalagem precisam ser facilmente } \\
\text { aprendidas, executadas e memorizadas. }\end{array}$ \\
\hline
\end{tabular}

Tabela 3. Aspectos de interação utilizados nas análises (Adaptado de CUSHMAN \& ROSENBERG, 1991; NIELSEN, 1994; JORDAN, 1998; WERBACH \& HUNTER, 2012).

Cada um desses aspectos lida com questões específicas, não apenas da Usabilidade, mas também da Ergonomia. Na Usabilidade, são abordados tópicos de um produto em interação humana durante o uso, e como a interface do produto, isso é, sua superfície de leitura ou pele, é comunicada a este usuário. NIELSEN (2012, tradução dos autores) afirma que ela é "um atributo de qualidade que avalia o quanto a interface do usuário é fácil de usar. A palavra 'usabilidade' também se refere aos métodos para aprimorar esta facilidade de uso durante o processo de design".

A usabilidade afere cinco métricas básicas ao seu estudo de comunicação (NIELSEN, 2012, tradução dos autores). Primeiro, a aprendizibilidade ${ }^{2}$, que é a facilidade com que o usuário aprende sobre como usar um produto pela primeira vez; segundo, a eficiência, que é a velocidade com que eles realizam tarefas com o produto após aprender o uso. A terceira é a memorabilidade ${ }^{3}$, que trata de aferir o quão rápido usuários retomam a proficiência do uso após algum tempo sem interagir com o produto. Em quarto há os erros, em relação à quantidade, impacto e facilidade de recuperação da condição negativa; e finalmente, a quinta métrica, da satisfação, que estuda quanto prazerosa é a execução de atividades (WERBACH \& HUNTER, 2012).

Na questão da ergonomia, os aspectos físicos são estudados, dependendo menos da interface de comunicação e das questões gráfico-textuais. Ela é responsável por avaliar a interação humano-máquina e as questões de afordância, isso é, de impressão dos usuários sobre os produtos (KANNENGIESSER \& GERO, 2012). É justamente aqui que estão as questões de segurança e qualidade mais severas, pois estão diretamente ligadas à tangibilidade e à forma dos produtos (CUSHMAN \& ROSENBERG, 1991). No caso das embalagens, são exemplos de avaliação a da busca por quinas vivas e protuberâncias; da análise de texturas (já que cores são informacionais, sendo estudadas, portanto, pela Usabilidade), da vedação e da adequação às pegas por elas permitidas.

\section{Testes com as Embalagens}

O primeiro processo de avaliação com especialistas serviu como um conjunto piloto de testes, de forma a balizar o processo antes de realizá-lo com os usuários participantes. Nessa etapa, os mesmos procedimentos a serem aplicados com os usuários foram utilizados, só que de forma mais branda, a fim de se gerarem correções e melhorias aos protocolos. Também, foram levantadas questões importantes detectadas por esses especialistas já em relação à qualidade dessas embalagens. Tendo em vista o número de questões para cada produto analisado bem como o quantitativo de usuários nos testes, foram executadas mais de três mil apreciações para tais produtos no compito geral, que conduziram as análises a seguir.

As avaliações com usuários procuraram avaliar a embalagem e observar como o usuário identifica a forma de uso. Observou-se como ele verifica onde abrir a embalagem e como ele a manuseia. Foi observado

\footnotetext{
${ }^{1}$ Termo que deriva do inglês "Affordance", sem tradução oficial atualmente para o português, para o que vem sendo tratado há anos em design por Norman (1999) que, neste contexto, pode ser destacado como o atributo ou a qualidade de um artefato o qual permite aos usuários identificarem a funcionalidade deste sem necessariamente uma explicação prévia.

${ }^{2}$ Como apresentado por Schütz e Schwengber (2018).

${ }^{3}$ Nilsen (2013) quando se refere a Usabilidade cita a "Memorabilidade" como um atributo de qualidade, sua tradução vem do termo em inglês "Memorability", mas de fato tende a ser uma palavra um pouco mais complexa de ser aplicada para a língua portuguesa.
} 
também caso ele procurasse alguma informação, como e onde ele o faz; e se prefere ler na embalagem ou perguntar a alguém. Esta etapa constava de quatro diretrizes (afirmativas) básicas em que o usuário apontava em que grau concordava (ou discordava) de cada uma. Utilizou-se a seguinte configuração para gradação em termos de atendimento ou não das características avaliadas:

\begin{tabular}{|c|c|c|c|c|}
\hline \multicolumn{5}{|c|}{ Votação dos Itens } \\
\hline Não atende & Atende pouco & $\begin{array}{l}\text { Atende } \\
\text { razoavelmente }\end{array}$ & Atende bem & Atende plenamente \\
\hline 1 & 2 & 3 & 4 & 5 \\
\hline \multicolumn{5}{|c|}{ Significado dos Valores } \\
\hline Menor que 15 & De 15 a 24 & De 25 a 34 & De 35 a 44 & A partir de 45 \\
\hline
\end{tabular}

Tabela 4. Escala de avaliação dos resultados obtidos, onde cada voto representa uma faixa de pontos. $\mathrm{Na}$ tabela 4 acima o somatório das votações de ambos especialistas e usuários figura dentro de uma delas, para cada embalagem. Os resultados das Tabela 5 a 7 agrupam o somatório dos votos, com os apontamentos gerais separados por modelo e marca dos produtos estudados. Nelas, estão apenas os resultados relativos à Ergonomia e Usabilidade, sem considerar a satisfação subjetiva do usuário.

\begin{tabular}{|c|c|}
\hline \multicolumn{2}{|c|}{ Embalagens plásticas laminadas com lacre de fita } \\
\hline $\mathrm{BC} 1$ & $\begin{array}{l}31 \text { - Das embalagens de cereal, foi a que teve menor aceitação. As pessoas testadas afirmaram que } \\
\text { ela era "desagradável". A embalagem ainda tem textos com baixa legibilidade (fonte escura sobre } \\
\text { fundo escuro) e má qualidade da impressão. }\end{array}$ \\
\hline $\mathrm{BC} 2$ & $\begin{array}{l}34 \text { - Apesar de simples, a embalagem possui informações desnecessárias. Muitos textos com } \\
\text { caracteres minúsculos e, apesar de contrastarem bem com o fundo, são pouco legíveis. Não existe } \\
\text { hierarquia de informações, que estão contínuas numa mesma caixa de texto. }\end{array}$ \\
\hline BC3 & $\begin{array}{l}36 \text { - O sabor e o nome do produto se confundem. Contudo, um fator positivo é que a diagramação do } \\
\text { texto na vertical confere maior legibilidade das informações, pois economiza espaço para o uso das } \\
\text { informações. Ainda assim, as pessoas não gostaram da diagramação, pois estavam acostumadas com } \\
\text { o texto na horizontal. }\end{array}$ \\
\hline $\mathrm{BC} 4$ & $\begin{array}{l}35 \text { - A embalagem é visualmente desagradável, com informações impressas em sentido oposto à outra } \\
\text { parte da impressão (como se uma parte estivesse impressa de cabeça para baixo). }\end{array}$ \\
\hline BC5 & $\begin{array}{l}35 \text { - Há falta de sinceridade na apresentação do produto: a embalagem mais parece oferecer um } \\
\text { chocolate do que uma barra de cereal. }\end{array}$ \\
\hline BC6 & $\begin{array}{l}32 \text { - Há falta de sinceridade na apresentação produto, já que a embalagem também parece oferecer } \\
\text { um chocolate, em vez de uma barra de cereal. As cores do texto e do fundo não contrastam, e o } \\
\text { kerning é muito baixo entre alguns caracteres, e muito alto entre outros. }\end{array}$ \\
\hline BC7 & $\begin{array}{l}29 \text { - O uso de dois idiomas prejudicou a compreensão dos usuários. Alguns participantes gostaram da } \\
\text { identidade visual do produto, devido ao uso de cores como branco, marrom e bege, que se } \\
\text { assemelham muito mais ao chocolate e aos sabores mais consumidos. }\end{array}$ \\
\hline $\mathrm{BC} 8$ & $\begin{array}{l}33 \text { - Há muita inconsistência visual na embalagem. Ela lembra mais a embalagem de um chocolate do } \\
\text { que a de uma barra de cereal: a denominação "barra de cereais" é minúscula, enquanto o sabor é } \\
\text { evidenciado, dando a entender que o produto é o sabor que ele oferece. }\end{array}$ \\
\hline
\end{tabular}

Tabela 5. Somatório dos resultados e principais apontamentos dos participantes na interação com as embalagens plásticas laminadas com lacre de fita (Tipo I) (produção dos autores).

Conforme pode ser observado na tabela acima, os erros de maior incidência estão diretamente ligados à usabilidade textual, quando há pouca legibilidade das informações nutricionais, composição do alimento e dados técnicos do produto e da conservação dele. Além disso, a escolha de cores pode ser decisiva, tanto para aprimorar a qualidade visual dos textos, quando para aumentar a adoção do usuário ao produto. Os produtos precisam ser honestos quanto ao que vendem, deixando claro que são barras de cereal com sabores diversos.

\begin{tabular}{|l|l|}
\hline Embalagem metálica com abertura tipo “anel" \\
\hline AN1 & $\begin{array}{l}\mathbf{3 4} \text { - Além de não deixar evidente o que produto oferece (a marca está em muito maior evidência que o } \\
\text { nome do produto), a tonalidade e espessura dos caracteres de texto dificultam sua legibilidade. Um ponto } \\
\text { positivo da embalagem é a textura de sua parte superior: apesar de não ter sido intencional (a variação de } \\
\text { textura tem a ver com o fabricante das latas, que possui um padrão de fôrma específico no corte, dobra e } \\
\text { moldagem das chapas), ela acaba por ser um fator que poderia ser explorado como forma de inclusão } \\
\text { para pessoas com deficiência visual. }\end{array}$ \\
\hline
\end{tabular}




\begin{tabular}{|l|l|}
\hline AN2 & $\begin{array}{l}\text { 32 - É uma das melhoras embalagens de enlatado, sendo seu maior defeito o tamanho dos caracteres de } \\
\text { texto. Vale salientar que foi preciso bastante cuidado para discernir bem as respostas dos usuários, pela } \\
\text { influência que a marca AN2 possui e como ela enviesa os sujeitos a uma resposta positiva. }\end{array}$ \\
\hline AN3 & $\begin{array}{l}\text { 35 - Esta embalagem deixa evidente o tipo de produto que oferece e sua identidade visual foi bem aceita, } \\
\text { apesar de a colocação do logo junto com o nome do produto gerar ambiguidade - dá a entender, segundo } \\
\text { muitos participantes, que há oitenta e oito sardinhas na lata - e não ser uma embalagem muito atrativa. A } \\
\text { validade também não está numa posição favorável. }\end{array}$ \\
\hline AN4 & $\begin{array}{l}\mathbf{3 2} \text { - É uma das mais simples dentre os enlatados, mas essa simplicidade acaba prejudicando as } \\
\text { informações na lata. Mesmo com tanto espaço livre, as informações têm caracteres muito pequenos em } \\
\text { áreas distantes umas das outras. Há também quatro tipos diferentes de famílias tipográficas e pouco } \\
\text { contraste entre texto e fundo. }\end{array}$ \\
\hline AN5 & $\begin{array}{l}\text { 34-É uma das embalagens de enlatado mais completas dentre as avaliadas, pois além de conseguir } \\
\text { passar todas as informações sobre a embalagem e o produto, ainda consegue colocar outras informações } \\
\text { que não tem importância direta para o usuário sem criar competição entre as informações. Seus maiores } \\
\text { problemas são o uso de fontes pequenas e baixa visibilidade de algumas informações importantes (há } \\
\text { pouco contraste entre os caracteres e o ícone com o fundo da zona do tutorial de abertura da lata). A } \\
\text { embalagem também é muito fiel quanto ao produto em seu conteúdo. }\end{array}$ \\
\hline AN6 & $\begin{array}{l}\text { 31 - Apesar da aceitação visual por parte da grande maioria dos usuários, esta embalagem possui um } \\
\text { dos sintomas mais negativos, que pesaram para sua reprovação: o fato de afirmar algo que não existe. } \\
\text { Isso porque ela afirma que há instruções de abertura na parte superior da lata, quando na verdade não } \\
\text { existem. Ainda avaliando toda a extensão da lata, para o caso de ter ocorrido apenas algum erro na } \\
\text { impressão e ela ter sido num lugar diferente do citado, foi comprovada a ausência do tutorial ou de } \\
\text { informações de abertura. }\end{array}$ \\
\hline
\end{tabular}

Tabela 6. Somatório dos resultados e principais apontamentos dos participantes na interação com as embalagens metálicas com abertura tipo "anel” (Tipo II) (produção dos autores).

Além dessas questões, um fator comum às embalagens de enlatado com alças de abertura (anel) está no risco de acidentes que estes mecanismos podem causar: um dos usuários participantes sofreu uma leve laceração na mão enquanto tentava abrir uma das latas, além de afirmar não possuir força o suficiente para conseguir abri-la sem se esforçar demasiadamente. As bordas das latas também ficam com serrilhados muito perigosos às mãos.

\begin{tabular}{|c|c|}
\hline \multicolumn{2}{|c|}{$\begin{array}{l}\text { Média dos resultados e principais apontamentos } \\
\text { (Ergonomia e usabilidade) }\end{array}$} \\
\hline PB1 & $\begin{array}{l}31 \text { - Possui exageros visuais: emprega cinco vezes sua logomarca, em cada um dos extremos da frente da } \\
\text { embalagem, mais uma vez na parte inferior da face de trás. Suas cores causaram estranhamento na maior parte } \\
\text { dos participantes, que afirmaram não entender que aquela embalagem é de pão bisnaga, não fosse pela } \\
\text { possibilidade de ver o produto no interior. }\end{array}$ \\
\hline PB2 & $\begin{array}{l}35 \text { - Das embalagens de pão, é a que mais possui falhas em sua identidade visual, pois o uso das cores azul e } \\
\text { roxo geraram desconforto, apesar do uso de um personagem famoso, tema da embalagem. O excesso de } \\
\text { atenção dado a ele distancia o usuário da verdadeira qualidade que se espera do produto. A tipografia branca } \\
\text { sobre o fundo azul claro dificulta ainda mais a leitura dos textos, que são vagos quanto ao produto. O emprego } \\
\text { de jogos também não é aconselhável para este tipo de embalagem, por consumir muito espaço útil. }\end{array}$ \\
\hline PB3 & $\begin{array}{l}\text { 33 - Foi uma das embalagens plásticas que apresentou melhor desempenho, em grande parte devido a sua } \\
\text { identidade visual chamativa e sucinta e pela honestidade com que o produto é apresentado. Contudo, pode } \\
\text { haver certo enviesamento das respostas dos usuários pelo fato de ser uma marca de grande influência. Apesar } \\
\text { de grande parte do público-alvo das bisnagas ser o infantil, o uso de mascotes e metáforas visuais ainda é } \\
\text { discutível, pois não afeta a qualidade da embalagem, mas pode retirar a atenção do usuário da qualidade do } \\
\text { produto para a forma como se apresenta, induzindo à compra. Os textos são objetivos e contrastam bem com o } \\
\text { fundo. Não é aconselhável a impressão da validade numa região do corpo da mascote. }\end{array}$ \\
\hline MP1 & $\begin{array}{l}31 \text { - Apresenta problemas para abertura da embalagem. Utiliza também brilho externo em seus caracteres de } \\
\text { texto, que quase não possuem contraste com o fundo em que foram sobrepostos, além dos caracteres serem } \\
\text { muito pequenos. }\end{array}$ \\
\hline MP2 & $\begin{array}{l}34 \text { - Das embalagens de macarrão, é a que apresenta melhor resultado, já que há simplicidade visual. As cores } \\
\text { que utiliza são sintonizadas com o produto que a embalagem apresenta. No geral, as informações são objetivas } \\
\text { e contrastam bem com o fundo, apesar do uso caligráfico de fontes ser desaconselhável. A embalagem } \\
\text { conseguiu manter um padrão muito bem aceito pelos usuários. }\end{array}$ \\
\hline MP3 & $\begin{array}{l}35 \text { - A embalagem apresenta uma maior resistência no material se comparada às de pão, o que a torna menos } \\
\text { suscetíveis às possíveis avarias da embalagem, mas também ficam mais difíceis de abrir - alguns dos sujeitos } \\
\text { avaliados afirmaram precisar de uma tesoura ou faca para abri-las. Vale destacar que dentre todos três pacotes } \\
\text { estudados, foi a que recebeu mais críticas pela sua identidade visual pobre (a imagem do garfo e do macarrão } \\
\text { foram mal recortados e estão visivelmente mal colocados sobre a embalagem. }\end{array}$ \\
\hline
\end{tabular}

Tabela 7. Somatório dos resultados e principais apontamentos dos participantes na interação com as embalagens plásticas com lacre de contato (Tipo III) (produção dos autores). 
Apesar de se tratar do mesmo modelo de embalagem, o material usado nas de pão é um pouco mais frágil, talvez pelo fato deste produto ser mais consumido diariamente que o macarrão. Assim, embalagens plásticas de pão podem ser abertas mais facilmente, mas também sofrem avarias com mais facilidade. $O$ caso das embalagens de macarrão é o exato oposto: são mais fortes, mas de abertura mais difícil.

De acordo com os resultados apresentados nas tabelas, nenhuma embalagem obteve níveis excepcionais de ergonomia ou usabilidade, sendo que apenas seis embalagens alcançaram bons resultados: $\mathrm{BC} 3, \mathrm{BC} 4$ e $\mathrm{BC} 5$; AN3; PB2 e MP3. As demais alcançaram níveis razoáveis de qualidade e segurança, já que não traziam nenhum risco grave à saúde e ao bem-estar dos usuários e especialistas participantes. A maior parte dos problemas de todas elas, inclusive das aprovadas, é em relação à quantidade e à estética dos textos, além de algumas terem uma identidade visual muito pobre.

É importante salientar que as notas dadas à ergonomia e à usabilidade não refletem necessariamente à satisfação do usuário, já que muitas das questões que se mostraram relevantes à adoção ou não de um dos produtos era mais ligada a questões subjetivas. Esses pontos significam que para os usuários, não importa a qualidade mecânica ou gráfica do produto, e sim, como estes produtos despertam a curiosidade e formam algum vínculo emocional com eles: isso é uma questão de afordância (KANNENGIESSER \& GERO, 2012).

É ela a principal responsável pelo sucesso do produto em gerar satisfação. Dessa maneira, as tabelas anteriores demonstram o que foi analisado levando-se todas as características apresentadas, exceto pela análise com o SUS - System Usability Scale (BROOKE, 1986), na qual foi utilizado o padrão proposto para Satisfação e Experiência de Uso, em ordem decrescente de resultados para cada grupo de embalagem analisado. $\mathrm{O}$ resultado dessa análise está descrito na Tabela 8 que segue:

\begin{tabular}{|c|c|c|c|c|c|}
\hline Embalagem Tipo I & Média SUS & Embalagem Tipo II & Média SUS & Embalagem Tipo III & Média SUS \\
\hline BC3 & 93 & AN5 & 78 & MP2 & AN3 \\
\hline BC4 & AN3 & AN4 & 71 & MP3 & 87 \\
\hline Nestle & 87 & AN1 & 70 & PB3 & 85 \\
\hline BC8 & 85 & AN2 & 69 & PB2 & 81 \\
\hline BC5 & 84 & AN3 & 68 & PB1 & 78 \\
\hline BC6 & 82 & AN6 & 63 & MP1 & 78 \\
\hline $\mathrm{BC7}$ & 81 & \multirow{2}{*}{\multicolumn{4}{|c|}{ Total de 20 embalagens avaliadas. }} \\
\hline $\mathrm{BC1}$ & 66 & & & & \\
\hline
\end{tabular}

Tabela 8. Resultado da aplicação do SUS com os participantes (produção dos autores).

Não foi aplicado um questionário individual do SUS com os usuários. Suas questões estavam agrupadas junto às de Ergonomia e Usabilidade. Isso economizou tempo das aplicações, sem perder-se o objetivo do sistema, para diminuir o cansaço na realização das análises, tanto dos pesquisadores quanto dos respondentes. Considerando-se que qualquer artefato/produto deve estar o mais próximo de 100 pontos, dentro da Escala de Usabilidade descrita nessa pesquisa e apontada para avaliação, apenas uma embalagem se apresenta realmente como próxima a este ideal: não por coincidência, nas análises de ergonomia e usabilidade apresentadas anteriormente, a mais bem classificada também foi a marca BC3.

Apenas uma embalagem do Tipo I não obteve bons níveis tão elevados de aceitação: a barra de cereal BC1, devido às más associações visuais que suas figuras provocaram nos usuários, atingiu baixa pontuação. As embalagens de barra de cereal têm em comum um fator problemático que vai além das questões ergonômicas: o tamanho da embalagem por unidade. Sendo um produto visivelmente pequeno, não pode ter uma embalagem muito maior que ele, pois não seria adequado. Só que por ser pequeno e ainda assim ser um produto de tantas características importantes, torna-se necessário reduzir a quantidade de informações e o tamanho dos ícones e caracteres até um valor suportável.

Das embalagens Tipo II, três não alcançaram resultados tão bons: AN2, AN3 e AN6. Isso mostra que, apesar de uma embalagem possuir ergonomia e usabilidade satisfatórios, eles podem, ainda assim, ter pouca adesão do usuário. Contudo, os enlatados tiveram os resultados mais equilibrados, se comparados com as demais 
embalagens. Isso porque muitas dificuldades de interação se deram mais pelo mecanismo de abertura do que pela qualidade gráfica das embalagens. A grande maioria (em geral, as mulheres) dos usuários testados não se sentiu muito confiante com o tipo de abertura, pois teriam que usar força física para abri-las.

Além disso, o fato do material ser metal tornou os usuários ainda menos confiantes, pois afirmaram ter medo de se cortar, se sujar ou mesmo derrubar as embalagens nos pés - situações que ocorreram com a grande maioria deles. Ademais desses fatores, muitas não apresentam informações de fácil visualização (o próprio tutorial de abertura não é visível ou bem esclarecido) ou boa diagramação do texto.

Já no Tipo III, todas as embalagens alcançaram bons resultados. Este tipo de embalagem é bastante comum na maior parte dos produtos de consumo não duráveis, em geral alimentos, e é o tipo de embalagem mais usada por este segmento da indústria. No geral, ela possui resistência o suficiente para ser transportada e manuseada com relativa facilidade, mas ainda é sujeita às avarias, como furos, mudança de composição pelo calor e aberturas irregulares promovidas pela má selagem das aberturas da embalagem - as de macarrão são mais fortes e, por consequência, mais difíceis de serem abertas.

Isso a torna facilmente rompível, pois a depender da força exercida, se inferior à necessária, é difícil abrir a embalagem por sua rigidez e, se superior, a embalagem corre o risco de rasgar no meio, na direção de cima para baixo ou ainda promover rasgos irregulares. Além disso, a textura lisa, apesar de estar razoavelmente adequada ao custo-benefício do produto, acaba por agravar o problema citado acima. Em nenhuma delas há alguma forma de prevenção de aberturas irregulares ou mesmo de lacrá-las novamente em caso de sobra ou abertura acidental.

\section{Conclusões}

Neste artigo, foram produzidas recomendações gerais ao design de três tipos de embalagem, a partir de testes de usabilidade e satisfação com usuários interagindo com vinte marcas de embalagens de bens de consumo não-duráveis, mais especificamente, pacotes plásticos de macarrão e pão do tipo bisnaga; enlatados; e barras de cereal. Cada embalagem compartilhava componentes estéticos e funcionais entre si, mas também apresentavam variações importantes e específicas de acordo com cada fabricante. Todas as etapas foram acompanhadas pelo Inmetro e validadas com estes o que resultou na reportagem feita no Fantástico que apontou as falhas e este teve retorno de vários fabricantes com relação a positividade de estudos com esse escopo, cuja metodologia foi validade pelo Órgão.

Dessa forma, tão importante quanto gerar soluções para cada marca e embalagem, foi a identificação de erros comuns aos três modelos-base desses artefatos, de forma que tanto estes quanto outros fabricantes possam evitar erros na escolha da embalagem ideal para seus produtos. Nesse caso, é imprescindível tentar compreender como seus projetos gráficos das informações são pensados e adicionados ao corpo dessas embalagens, e que reação o conjunto das obras provoca em seus usuários (CUSHMAN \& ROSENBERG, 1991; adaptação dos autores).

Não obstante, muitos desses artefatos já alteraram seu design, desde o ano de 2014, quando o estudo foi realizado, até agora. Contudo, as recomendações aqui apresentadas não dependem exclusivamente dessas marcas e dessas embalagens, mas dos erros comuns de ergonomia e de usabilidade que são recorrentes neste tipo de produto. Dessa forma, é preciso atentar para questões de qualidade da informação, da comunicação, da segurança, do conforto e do apelo estético independente da marca e do tipo de embalagem.

\subsection{Obstáculos à Pesquisa}

Dentre os principais obstáculos durante o processo de pesquisa, destaca-se a diversidade das embalagens estudadas, todas com características muito específicas quanto aos materiais e aos processos de fabricação: as 
necessidades industriais para a fabricação enlatados são muito diferentes daquelas para a fabricação de um plástico laminado ou de um saco plástico com vedação por prensa. Dessa forma, mesmo que alguns aspectos de design fossem comuns a todas, cada tipo pediu por estudos específicos.

Segundo, ao desenvolver uma jornada de teste para aplicação com os usuários que não fosse extenuante, já que, pela quantidade de embalagens estudadas, era impossível criar testes com duração total inferior a duas horas. Contudo, algumas ações foram tomadas para evitar o cansaço ou a ansiedade dos participantes, por exemplo, os testes eram aplicados em horário comercial, no turno da tarde, com intervalos. O protocolo focava sempre em períodos que não houvesse impedimentos nem aos participantes nem aos pesquisadores.

\subsection{Futuros Trabalhos}

Para concretizar um conjunto de análises ainda mais sólido, é importante que mais embalagens de outros fabricantes sejam avaliadas, preferencialmente, de modelos do mesmo tipo, mas com variações no fechamento, nos materiais e no formato das embalagens. Também, que as atuais embalagens dos mesmos produtos sejam estudadas, para entender que mudanças elas sofreram a fim de melhorar a usabilidade e a ergonomia, tendo em vista que os fabricantes receberam os resultados do Inmetro a fim de facilitar possíveis aprimoramentos. Em tempo ressalta-se que quase todas as empresas se pronunciaram e destacaram que iriam resolver os problemas apontados.

Por fim, estudos de usabilidade dos produtos não-digitais são cada vez mais comuns, sendo importante aumentar continuamente a gama de artefatos que podem ser submetidos às análises de qualidade da interação, da informação e da comunicação. Futuras pesquisas deverão potencializar a parceria do Inmetro com a Universidade Federal de Pernambuco, a fim de facilitar o estudo das embalagens e de outros produtos, para maiores contribuições da academia à indústria de bens de consumo.

\section{Referências Bibliográficas}

ABNT. Conheça a ABNT. Disponível em: http://abnt.org.br/abnt/conheca-a-abnt. Acesso em: 10 ago. 2020.

BROOKE, J.. SUS: a "quick and dirty" usability scale. In P. W. Jordan; B. Thomas; B. A. Weerdmeester; A. L. McClelland (eds.). Usability Evaluation in Industry. London: Taylor \& Francis, 1986.

CUSHMAN, W. H.; ROSENBERG, D. J.. Human Factors in Product Design. - 1 ed. - Amsterdam: Elsevier, 1991.

FANTÁSTICO - REDE GLOBO. Inmetro analisa usabilidade de embalagens de 20 marcas (2015). Disponível em: http://g1.globo.com/fantastico/noticia/2015/05/inmetro-analisa-usabilidade-de-embalagensde-20-marcas.html. Acessado em 07/12/2020.

GIGERENZER, G.; GAISSMEIER, W.. Heuristic Decision Making. In Annual Review of Psychology, Vol. 62, pp. 451-482, 2011.

Inmetro analisa usabilidade de embalagens de 20 marcas. Rio de Janeiro: Globo Comunicação e Participações, 2015. Disponível em: http://g1.globo.com/fantastico/noticia/2015/05/inmetro-analisausabilidade-de-embalagens-de-20-marcas.html. Acesso em: 27 set. 2020.

INMETRO. Acesso à Informação. Disponível em: http://www4.inmetro.gov.br/acesso-ainformacao/institucional. Acesso em: 27 set. 2020.

ISO. About Us. Disponível em: https://www.iso.org/about-us.html. Acesso em: 27 set. 2020. 
ISO. ISO/IEC Guide 37: Instructions for use of products by consumers. International Organization for Standardization, 2012.

JORDAN, P. W.. An Introduction to Usability / Patrick W. Jordan. - 1 ed. - Florida: CRC Press, 1998.

Kannengiesser, U.; Gero, J. S.. A Process Framework of Affordances in Design. In Design Issues, v. 28, n. 1, p. 50-62, 2012.

Laboratórios. Recife: Universidade Federal de Pernambuco, 2020. Disponível em: https://www.ufpe.br/progest/laboratorios. Acesso em: 27 set. 2020.

MAgAlHÃes, T. A. Valor da Marca para o Consumidor: Um Estudo Empírico no Setor Automotivo. Dissertação de Mestrado. Belo Horizonte. Universidade Fumec, 2006.

MORGAN, G. A.. Quasi-Experimental Designs. In Journal of the American Academy of Child \& Adolescent Psychiatry. Vol. 39, 6, pp: 794-796, 2000.

NORMAN, D. A. Affordance, Conventions, and Design. Interactions, vol. 6, no 3, p. 38-43, 1999. DOI.org (Crossref), doi:10.1145/301153.301168

NIELSEN, Jacob. 10 Heuristics for User Interface Design. California: NN/G, 1994. Disponível em: https://www.nngroup.com/articles/ten-usability-heuristics/. Acesso em: 26 set. 2020.

NIELSEN, Jacob. Usability 101: Introduction to Usability. California: NN/G, 2012. Disponível em: https://www.nngroup.com/articles/usability-101-introduction-to-usability/. Acesso em: 26 set. 2020.

NILSEN, J. Experience, World Leaders in Research-Based User. "Usability 101: Introduction to Usability". NNG, 2013. https://www.nngroup.com/articles/usability-101-introduction-to-usability/. Acessado 28 de julho de 2021

RIO DE JANEIRO. Guia de Embalagens: Rio 2016. Comitê Organizador dos Jogos Olímpicos e Paralímpicos Rio 2016, 2013.

SCHÜTZ, J. e SCHWENGBER, I.. Sobre a ensinabilidade e a aprendizibilidade da filosofia: reflexões acerca da especificidade do exercício filosófico. Filosofia e Educação, 10. 331-349, 2018. 10.20396/rfe.v10i2.8651165.

SOARES, M. M. Translating User Needs Into Product Design for Disabled People: a study of wheelchairs. Doctorate's Thesys. UK, Loughborough University, 1998.

WERBACH, K.; HUNTER, D.. For the Win: How Game Thinking Can Revolutionize Your Business. 1 ed. - Philadelphia: Wharton Digital Press, 2012.

\section{Agradecimentos}

Agradecemos à Universidade Federal de Pernambuco (UFPE) pelo contínuo apoio aos Laboratórios do Departamento de Design do Programa de Pós-Graduação em Design do Centro de Artes e Comunicação; ao CNPq por acreditar nas ações do Laboratório de Concepção e Análise de Artefatos Inteligentes (LACA ${ }^{2}$ I), e agradecemos ao ainda Inmetro pela confiança e pelo reconhecimento do trabalho nesta parceria para sugerir melhorias no design de embalagens de produtos altamente consumidos no Brasil. 